\title{
High-frequency respiratory input impedance measurements in infants assessed by the high speed interrupter technique
}

\author{
U. Frey*, M. Silverman*, R. Kraemer**, A.C. Jackson*
}

High-frequency respiratory input impedance measurements in infants assessed by the high speed interrupter technique. U. Frey, M. Silverman, R. Kraemer, A.C. Jackson. (OERS Journals Ltd 1998.

ABSTRACT: High-frequency input impedance $(Z(f))$ measurements, including antiresonances, provide useful noninvasive information on airway geometry and especially airway wall mechanics in the canine and human adult respiratory system. A knowledge of airway wall mechanics would be particularly important in understanding flow limitation phenomena in infants. High-frequency $Z(f)$ has not been measured in infants above $256 \mathrm{~Hz}$, because the high impedance of the infantile respiratory system would be expected to result in low amplitudes of oscillatory flow at higher frequencies. The aim of this study was to develop a technique to measure high-frequency $Z(f)$ in infants and to elucidate the nature of the antiresonance phenomena in the $Z(f)$ spectrum in infants.

$Z(f)$ was measured from 32-900 $\mathrm{Hz}$ during rapid airflow interruption by the highspeed interrupter technique (HIT) in 18 infants (aged 24-149 weeks) with wheezing disorders. The HIT enables the excitement of higher flow amplitudes at high frequencies using a pseudostep forcing function.

In all infants $Z(f)$ showed a mean (sD) first antiresonance ( $f$ ar,1) of $172(35) \mathrm{Hz}$ (real part of $Z(f)$ at $f$ ar,1 $(Z(f)$ re $(f a r, 1)): 4.9(1.1) ~ k P a \cdot L \cdot 1 \cdot s)$ and in five infants a second antiresonance $(f a r, 2)$ of $564(51) \mathrm{Hz}\left(Z(f) \mathrm{re}(f \mathrm{ar}, 2): 2.0(0.7) \mathrm{kPa} \cdot \mathrm{L}^{-1} \cdot \mathrm{s}\right)$. The antiresonances were found to be related to wave propagation in the airways (acoustic antiresonances), because they increased by a factor of $\sim 2$ when $\mathrm{He}-\mathrm{O}_{2}$ was inhaled. This implies that $f_{\text {ar, }} 1$ and its harmonics are a function of airway wall compliance.

In conclusion, the first and second antiresonances may be helpful in understanding flow limitation in wheezing disorders in infants, because flow limitation is related not only to airway diameter but also to airway wall compliance. Eur Respir J 1998; 12: 148-159.

In infants and toddlers suffering from wheezing disorders, lung function testing for diagnosis and the monitoring of therapy is technically difficult and patients usually need to be sedated. The rapid thoracic compression (RTC) technique has been shown to be a simple and reproducible method to assess flow limitation in infants [1]. Maximum flows achieved during expiration are directly related to airway cross-sectional area (calibre) and inversely related to airway wall compliance [2], so that the technique cannot determine the contribution of these two properties to overall airway function. For instance, bronchodilator agents can cause both an increase in airway calibre and, by removing airway smooth muscle tone, an increase in airway wall compliance. Their effect on maximum expiratory flow would be determined by both the baseline conditions of airway calibre and airway wall compliance and the relative changes induced, since an increase in calibre and airway wall compliance will have opposite effects on maximum flow rates. The RTC can therefore sometimes lead to paradoxical results when the effect of inhaled bronchodilators is tested in infants [3]. In order to understand better the role of physiological development of the airways in foetal life and infancy for later airway disease [4] and to understand wheezing disorders and drug action
*Dept of Child Health, University of Leicester School of Medicine, Leicester, UK. **Dept of Paediatrics, University of Berne, Berne, Switzerland. ‡Dept of Biomedical Engineering, Boston University, Boston, MA, USA

Correspondence: U. Frey

Dept of Paediatrics

University Hospital of Bern

Inselspital

3010 Bern

Switzerland

Fax: 41316329468

Keywords: Airway wall

forced oscillation technique

interrupter technique

respiratory impedance

respiratory mechanics

wheezing

Received: March 171997

Accepted after revision March 131998

UF was supported by a grant from the Swiss National Science Foundation (Stipendium für angehende Forscher der Forschungskommission der schweizerischen Nationalfonds) in infancy, there is a need for a noninvasive lung function technique that provides a measure of airway wall properties independent of airway calibre.

Measurements of respiratory input impedance $(Z(f))$ can be made noninvasively over a wide range of frequencies within seconds without patient cooperation. The technique has been used to measure lung function in dogs [5-9] and in human adults [10-14]. Even though $Z(f)$ measurements were proposed several years ago as a potentially useful test of infant lung function, until recently, only $Z(f)$ data at frequencies $<100 \mathrm{~Hz}$ have been reported in infants [15-18]. If information regarding airway wall properties is required, $Z(f)$ data should be measured at higher frequencies [19, 20]. An important feature of the high-frequency impedance spectrum is the presence of an antiresonance, defined by the zero-crossing in the imaginary part in the presence of a relative maximum in the real part. In infants, the exact nature of these antiresonances has not been completely elucidated. In human adults it is known that $Z(f)$ at frequencies $>100 \mathrm{~Hz}$ (in particular antiresonances) is influenced by airway resistance and airway wall properties and little by tissue properties.

Even though one can infer changes in airway wall properties from $Z(f)$ at frequencies that include only the first 
antiresonance $[19,20], Z(f)$ at frequencies that include additional antiresonances are needed before quantitative estimates of airway wall properties can be obtained $[8,9,14]$. Measurements of $Z(f)$ with loudspeaker-generated forced oscillations applied at the airway opening are problematic because infant airways are small and the respiratory system has a relatively high impedance. Therefore, if pressure waves are applied at the airway opening, the amplitude of the resulting flow will be small and the signal-to-noise ratio will be low. This is particularly true for higher frequencies because of the capacitative shunting into the gas compression compliance of the loudspeaker dead-space.

To overcome these problems a new technique was developed, the high-speed interrupter technique (HIT) [21], which uses a pseudostep flow-forcing function and enables much higher flow amplitudes at high frequencies than the forced oscillation technique (FOT).

The aim of the current study was to determine whether it is technically possible to measure coherent high-frequency $Z(f)$ in infants using the HIT and whether the baseline variability of the antiresonance features is similar to the variability of a reference lung function technique such as RTC. A further aim was to determine whether these antiresonances were related to wave propagation phenomena in the airways as in adults, which would imply that the frequency of the first antiresonance was a function of airway wall properties independent of airway calibre. A final aim was to measure whether patency of the upper airways might influence high-frequency $Z(f)$.

\section{Physiological background}

$Z(f)$ data have been analysed either using systems identification techniques $[5-8,11,14-16,18,22]$ or by considering changes in specific features of the $Z(f)$ spectra $[12,13,17]$. For example, in adults the level of airway obstruction is directly related to the amount of negative frequency dependence in the real part of $Z(f)(Z(f)$ re) and the frequency of the resonance (where the $Z(f)$ re is a relative minimum and the imaginary part $Z(f)$ im crosses zero) as well as inversely related to the frequency of the antiresonance (where the $Z(f)$ re is a relative maximum and $Z(f)$ im crosses zero) [12]. Unlike feature analysis, systems identification techniques provide estimates of physiological parameters by fitting a model to the $Z(f)$ data. One such model, the Dubois six-element model [22] provides separate estimates of airway (Raw) and tissue resistance $(R \mathrm{ti})$, as well as thoracic gas volume $(V \mathrm{tg})$. However, this model can be used only if the $Z(f)$ data include an antiresonance that is related to the tissue inertance $(I \mathrm{ti})$ and the alveolar gas compression compliance $(C \mathrm{~g})$. There is such an antiresonance in dogs [5-7] and rabbits but not in adult humans $[10,11]$. Instead, the antiresonances in adults are due to wave-propagation phenomena and are thus related to inertance of the gas within the airways and the compliance of the airway walls $[10,11]$ Since the antiresonances are related to wave propagation, estimates of $R$ aw and $V \mathrm{tg}$ are not possible in human adults but inferences about airway wall properties are possible $[10,11]$. Even though the phenomena that contribute to antiresonances in infants are not clearly understood, preliminary results have indicated [19] that antiresonances could be related to the total respiratory system inertance ( $I r s)$ but also partly due to the gas compression compliance in the face mask. In order to determine whether anti-resonances are related to $I \mathrm{ti}$ and $C \mathrm{~g}$ or to wave-propagation phenomena, measurements of high-frequency impedance have to be taken using gases of different density $[10,11]$. So far, this has never been done in infants.

\section{Methods}

\section{Subjects}

The main study (part 1) was performed in 18 infants and young children (11 females and 7 males, aged 24-149 weeks) with a history of episodic or recurrent wheeze, who had been referred from the outpatient clinic for lung function tests as part of their clinical investigation (table 1). Physiological and technical aspects (parts 2 and 3 ) were studied in a separate group of six infants (three males and three females, aged 1-18 months). Infants with other severe diseases and infants with upper respiratory tract infection within the previous 3 weeks were not included in the study. The infants and toddlers were sedated using a maximum oral dose of $150 \mathrm{mg} \cdot \mathrm{kg}^{-1}$ triclofos sodium and lung function was measured during behaviourally defined quiet sleep. The additional HIT measurements were approved by the Ethics Committee of the Royal Postgraduate Medical School, Hammersmith Hospital, London, UK. Written consent was obtained from parents.

\section{Study design}

The study was performed in three parts. First, in 18 infants it was determined whether it was technically possible to measure high-frequency impedance. In these infants the variability (10 measurements) of the frequency and relative maxima in the real part at the antiresonances was determined, and compared to the variability of the maximal flow at functional residual capacity (FRC) ( $\left.V^{\prime} \operatorname{maxFRC}\right)$ by the RTC. Secondly (part 2), in three additional infants measurements of $Z(f)$ breathing a gas mixture of $21 \%$ oxy-

Table 1. - Physical characteristics of subjects

\begin{tabular}{lccccccc}
\hline Group & $\begin{array}{c}\text { Weight } \\
\mathrm{kg}\end{array}$ & $\begin{array}{c}\text { Height } \\
\mathrm{cm}\end{array}$ & $\begin{array}{c}\text { GA } \\
\text { weeks }\end{array}$ & $\begin{array}{c}\text { PNA } \\
\text { weeks }\end{array}$ & $\begin{array}{c}V^{\prime} \text { maxFRC } \\
\text { mean } \pm \text { sD } \\
\mathrm{mL} \cdot \mathrm{s}^{-1}\end{array}$ & $\begin{array}{c}\text { Pred. } \\
\text { for age } \\
\%\end{array}$ & $\begin{array}{c}\text { Pred. for } \\
\text { length } \\
\%\end{array}$ \\
\hline Mean & 9.7 & 75.6 & 38.9 & 51.5 & $213.6 \pm 11.6$ & 77.5 & 72.3 \\
SD & 1.7 & 8.2 & 2.8 & 19.6 & $89.5 \pm 5.4$ & 36.8 & 39.0 \\
Minimum & 6.8 & 63.0 & 30.0 & 24.0 & $78.9 \pm 6.5$ & 14.5 & 17.7 \\
Maximum & 16.0 & 95.6 & 41.0 & 148.6 & $409.0 \pm 23.7$ & 152.1 & 184.8 \\
\hline
\end{tabular}

GA: gestational age; PNA: postnatal age; $V$ 'maxFRC: maximal flow at functional residual capacity; $V^{\prime}$ maxFRC: maximum flow at functional residual capacity; Pred: predicted values from Ref [1]. 
gen and $79 \%$ helium (Heliox; $\mathrm{He}-\mathrm{O}_{2}$ ) were taken to elucidate the physiological basis of the antiresonances. If antiresonance in infants were related to wave-propagation phenomena, then the frequency at which antiresonance occurred would increase as a function of gas density. In a gas of lower density wave-propagation velocity would be faster and the frequency of the antiresonance in a tube would be higher. Thirdly (part 3), it was questioned whether the upper airways significantly influenced the antiresonances. This hypothesis was tested in three infants by measuring five sets of HIT measurements before and after occluding one nostril.

\section{High-speed interrupter technique for infants}

The principle of the HIT (fig. 1) has been described elsewhere [21] and is thus only described briefly here. The HIT is based on rapid multiple interruptions of airflow. If flow interruption were to occur instantaneously, the input flow signal applied to the lungs would be a step function, the frequency $(f)$ content of which varies as $1 / f$. The less rapidly the interruption occurs, the lower the amplitudes of the flow at higher frequencies. This interrupter is driven by a stepper motor (start speed $1,200 \mathrm{~Hz}$, maximal speed 7,500 Hz, ramp time $13 \mathrm{~ms}$ ). The shutter consists of a rotating blade which closes the airway opening within $1 \mathrm{~ms}$, remains closed for $15.5 \mathrm{~ms}$, then opens for another $15.5 \mathrm{~ms}$. Thus the complete interruption-closure cycle occurs once every $31 \mathrm{~ms}$. The motor is controlled by a digital-to-analogue converter (Model AT-MIO16; Natio-nal Instruments, Tx, USA). The position of the shutter valve (open or closed) was measured by a photooptic resistor to ensure that the shutter was reopened after an interruption so that the subject was able to breathe between the measurements. Whenever the interrupter was enabled, it triggered only at inspiratory flow rates of less than $0.1 \mathrm{~L} \cdot \mathrm{s}^{-1}$ producing five separate interruptions. The shutter mechanism was connected to the mouthpiece by a tube $14 \mathrm{~cm}$ in length of $1 \mathrm{~cm}$ internal diameter.

$Z(f)$ was measured using the wave tube technique described in detail elsewhere [8, 14, 21, 23]. In brief, in this technique pressures are measured at two locations (6.7 $\mathrm{cm}$ apart) along the tube between the shutter mechanism and the mouthpiece. The first pressure transducer $(P 1)$ was placed $3.3 \mathrm{~cm}$ and the second pressure transducer $(P 0) 10 \mathrm{~cm}$ from the airway opening (face mask). A

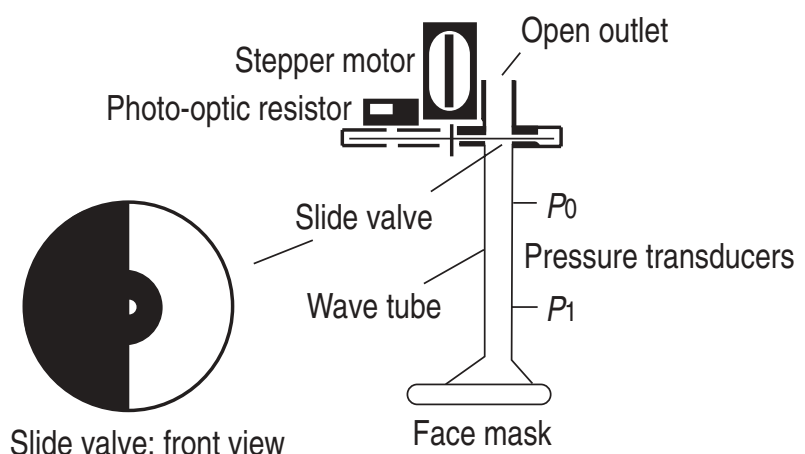

Fig. 1. - Using the noninvasive high-speed interrupter technique (HIT) high-frequency input impedance can be measured using a quickly rotating interrupter valve which generates a pseudo-step flow function. The resulting pressure and flow oscillations can be assessed using the wave tube technique [17].
Rendell Baker Soucek face mask (size 1; Ambu International, Bath, UK) was chosen because its dead space was small. In the process of study design different face masks were tried and their effect on high-frequency $Z(f)$ data studied. The dead space in the face mask was minimized to $10-15 \mathrm{~mL}$ by filling it as much as possible with putty (Therapeutic Putty, Carter's, Bridgend, UK). Z( $f$ ) was computed as the load impedance of the tube by:

$$
Z(f)=\frac{Z c \cdot \sinh \gamma L}{P 1 / P 0-\cosh \gamma L}
$$

where $L$ is the distance between the two pressure transducers $(6.7 \mathrm{~cm}), Z_{\mathrm{c}}$ is the characteristic impedance of the tube, and $\gamma$ is the propagation coefficient of the tube. $P 1$ and $P 0$ were measured with piezoelectric pressure transducers that were matched within $<2 \%$ in magnitude and $<2^{\circ}$ of phase (EuroSensor, Model 33; UK). The electrical output of these transducers was band-pass filtered $(8-2,000 \mathrm{~Hz})$ and converted from analogue to digital at $8,258 \mathrm{~Hz}$ (Model AT-MIO-16; National Instruments). Data were stored during five complete cycles of the interrupter (five times $31 \mathrm{~ms}=$ $155 \mathrm{~ms}$, with a sampling rate of $8,258 \mathrm{~Hz}$ ). The ratio of $P 1 /$ $P 0$ was estimated from the cross-power spectra of $P_{0} P 1$ and the auto power spectra of $P 1$ [24]. The length of the FFT window was 1,024 points. Control of the interrupter shutter, data acquisition, and computation of the crosspower and autopower spectra and their ratio were performed using Labview for Windows (National Instruments).

\section{Thoracic compression technique}

Partial expiratory flows at FRC ( $V$ 'maxFRC) were measured using the RTC technique $[1,3,25]$. The supine infants wore an inflatable polythene thoracoabdominal jacket (Medical Engineering Dept, Royal Postgraduate Medical School, London, UK) with the arms out. Flow was measured using a face mask (size 1, Rendell Baker Soucek, Ambu International) and Fleisch No. 1 (Gould, NE, USA) pneumotachograph and differential pressure transducers (Validyne MP45, Northridge, CA, USA). The linearity was estimated to be accurate within $2 \%$. The flow signals were converted from analogue to digital and assessed using RASP software (Physiologic, Newbury, UK). After a series of RTC measurements to determine the optimal jacket pressure, 10 RTC measurements were performed at end-tidal inspiration using this optimal jacket pressure. The mean value of all technically satisfactory values was determined. Transcutaneous oxygen tension $\left(\mathrm{PO}_{2}\right)$ (TMC3; Radiometer, Copenhagen, Denmark), and transcutaneous oxygen saturation $\left(\mathrm{Sa}_{\mathrm{a}} \mathrm{O}_{2}\right)$ (Biox 3740 ; Omeda, Omaha, NE, USA), were observed. The head position was standardized based on the experience of DESAGER et al. [17] but, for safety reasons the mouth was not taped. The head position was not changed between measurements using different techniques. The same face mask and putty filling were used for both techniques.

\section{Part 1: Description and repeatability of high-frequency impedance phenomena}

In order to test the short-term repeatability within a period of 10-15 min, 10 sets of $Z(f)$ measurements were performed during quiet, regular tidal breathing. Each measurement 

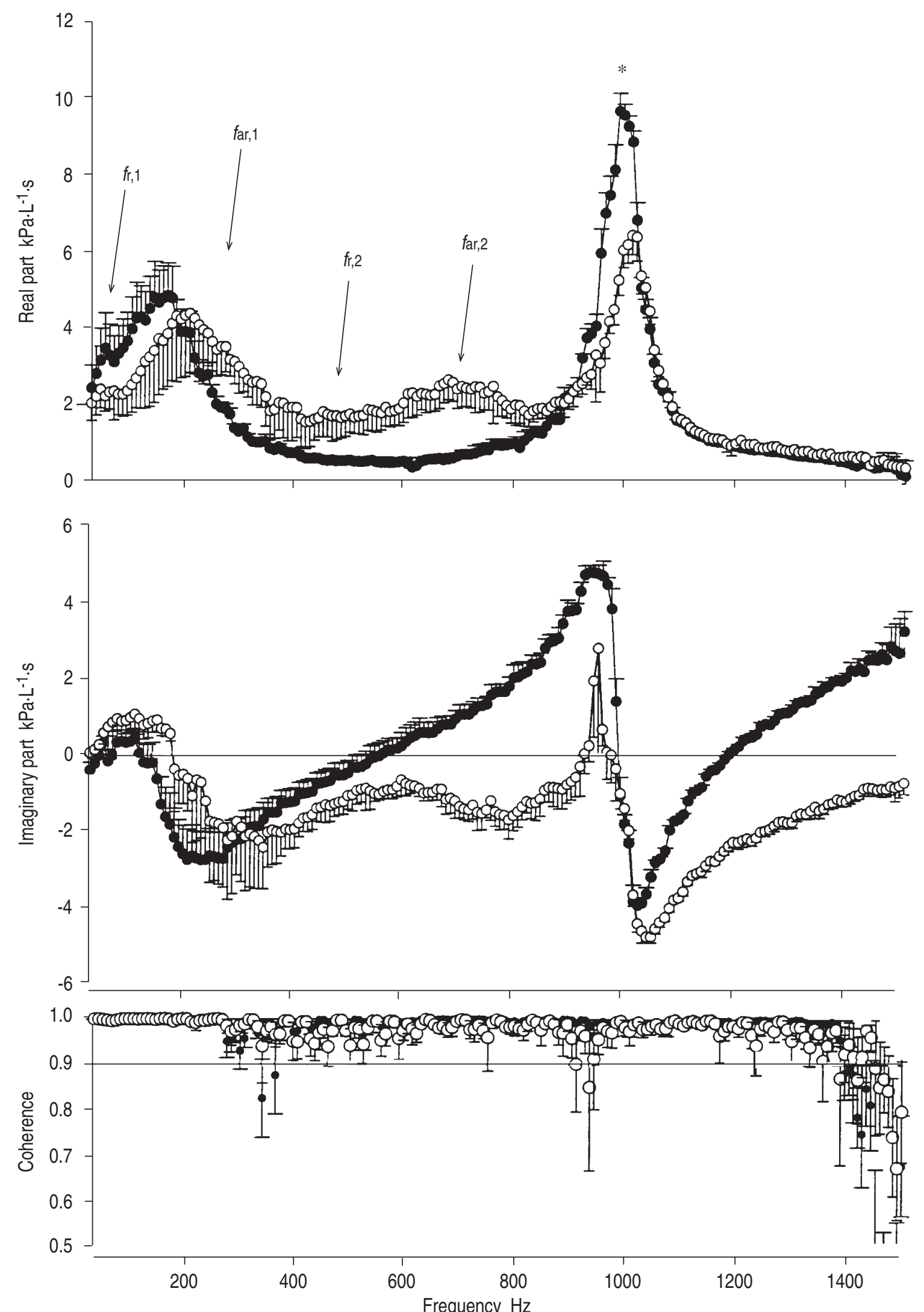

Fig. 2. - Mean impedance spectrum, SD (bars) and coherence from 10 input impedance measurements assessed by the high-speed interruptor technique in two representative infants $(\bullet$ : subject $11 ; 0$ : subject 5$)$. Both infants showed a first and second resonance frequency $\left(f_{\mathrm{r}, 1}\right.$ and $\left.f_{\mathrm{r}, 2}\right)$ and a first antiresonance $\left(f_{a r}, 1\right)$. Subject 5 showed a second antiresonance $\left(f_{\mathrm{ar},}, 2\right)$. A third antiresonance $\left(f_{\mathrm{ar}}, 3\right)$ at $\sim 1,000 \mathrm{~Hz}$ occurred in both infants, but was dependent on the set-up and the type of face mask (artefactual). Apart from single frequency points, which were excluded from the spectrum, the coherence was $>0.9$ from 32 to $\sim 1,300 \mathrm{~Hz}$. *: upper airway artefact. 
took $0.15 \mathrm{~s}$ at the beginning of inspiration. Airflow interruptions that did not show peak pressure changes of Š 0.15 $\mathrm{kPa}$ were not accepted. None of the infants was disturbed in sleep by the measurements, no symptoms occurred, and $\mathrm{PO}_{2}$ and $\mathrm{Sa}_{2} \mathrm{O}_{2}$ remained stable. Thereafter, the inflatable jacket was wrapped around the infant's chest and 10 forced expirations were performed. From each of the 10 sets of five airflow interruptions, $Z(f)$ and coherence $\gamma$ were calculated. The 10 sets were assessed during a period of 10-15 min to determine short-term repeatability. Only $Z(f)$ data with coherence $>0.90$ were accepted. If the coherence of the whole set of measurements was low the set was rejected. If the coherence of a few data points was $<0.9$, these particular frequency points were rejected and excluded from the spectrum. From the sets that fulfilled the criteria mentioned above, the mean and SD of the $Z(f)$ was calculated from $32 \mathrm{~Hz}$ to the maximal frequency with $\gamma>0.90(f \max \gamma)$. The $Z(f)$ was presented by complex numbers (real and imaginary part): short-term repeatability of frequency $(f a r, 1)$ and the relative maximum in the real part at $f \mathrm{ar}, 1(Z(f) \mathrm{re}(f \mathrm{ar}, 1))$ at the antiresonances were expressed by their coefficient of variation $(\mathrm{CV})$.

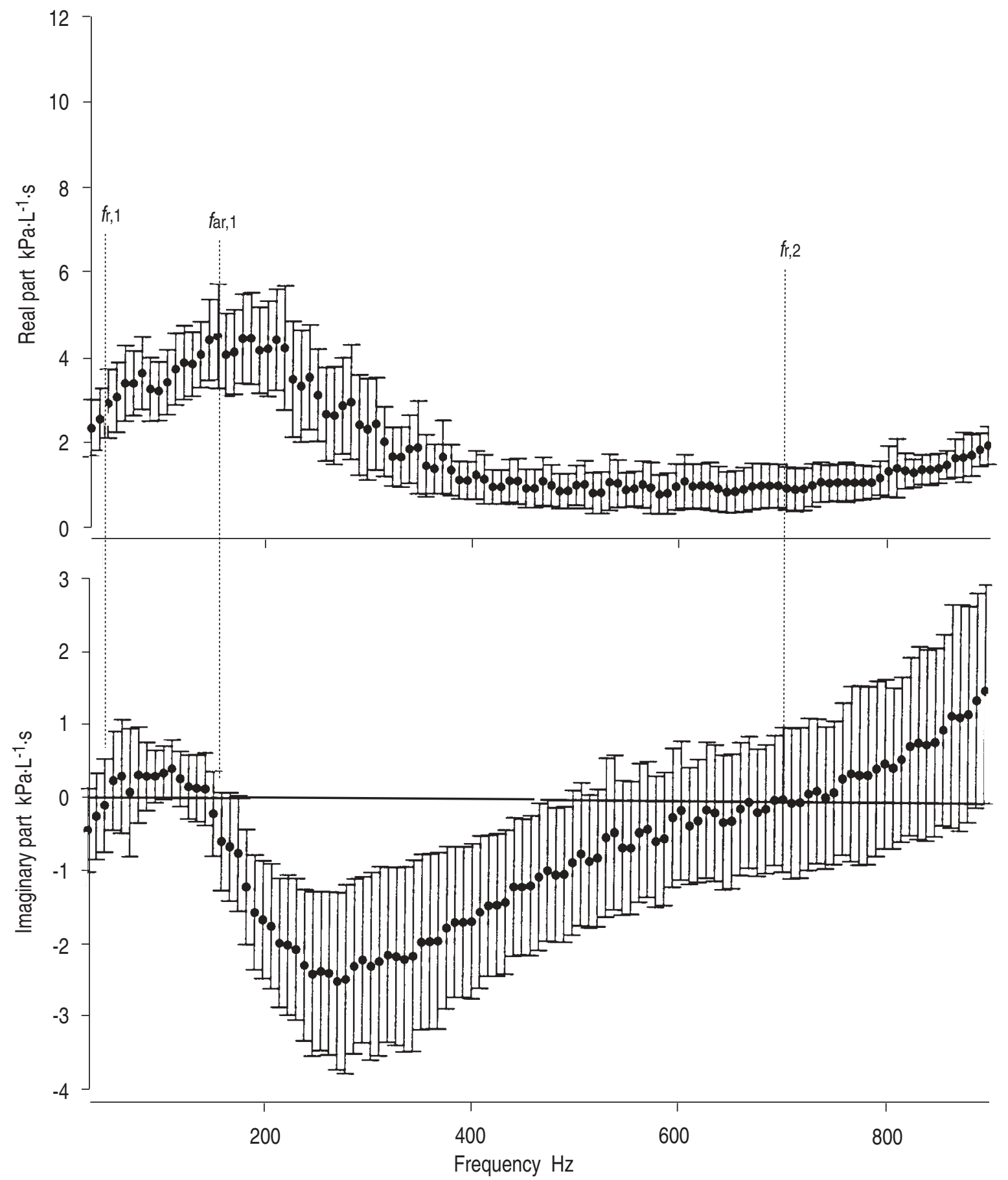

Fig. 3. - Impedance spectra (mean and SD for all 18 infants) from 32 to $900 \mathrm{~Hz}$, showing the first resonance frequency, $f_{\mathrm{r}, 1}(53 \pm 14 \mathrm{~Hz})$, the first antiresonance, $f_{\mathrm{ar}, 1}(172 \pm 35 \mathrm{~Hz})$ and the second resonance frequency, $\mathrm{fr}_{\mathrm{r}, 2}(762 \pm 158 \mathrm{~Hz})$. 
From the 10 forced expiratory manoeuvres the mean and SD of $V^{\prime}$ maxFRC were calculated as well as percentage predicted (for age) based on the reference values of TEPPER $e t$ al. [1]. Short-term repeatability $V^{\prime} \operatorname{maxFRC}$ was expres-sed by the CV. The differences in CV between the diff-erent parameters were compared using a nonparametric Wilcoxon test.

\section{Part 2: Measurements during Heliox $\left(\mathrm{He}-\mathrm{O}_{2}\right)$ breathing}

Five sets of $Z(f)$ measurements were collected in three infants (aged 1,9 and 12 months) during air breathing and during humidified Heliox $\left(\mathrm{He}-\mathrm{O}_{2}\right)$ breathing after $8-10$ min of equilibration.

\section{Part 3: Influence of nasal patency on $\mathrm{Z}(\mathrm{f})$}

In another three infants (aged 12, 12 and 18 months) the possibility was examined that high-frequency $Z(f)$ data were influenced by the upper airway patency. In each of these three infants, five sets of $Z(f)$ measurements were performed before and after the occlusion of one nostril by gentle pressure over the alae nasae and by putting therapeutic putty inside the face mask. During this $30 \mathrm{~s}$ manoeuvre $S_{\mathrm{a}, \mathrm{O}_{2}}$ was stable in all infants. With this manoeuvre the resistive and inertive properties of the upper airways were altered, without any direct alteration of the intrathoracic airway function.

\section{Results}

\section{Part 1: High-frequency impedance phenomena}

Representative examples of $Z(f)$ data in two subjects ( 5 and 11) are shown in figure 2 . All subjects showed similar high-frequency $Z(f)$. The real part of $Z(f)$ at $32 \mathrm{~Hz}$ was between 1.34-3.54 (mean $2.34 \pm 0.64$ ) $\mathrm{kPa} \mathrm{L}^{-1}$.s. In all but four of the subjects a first resonance was found above $32 \mathrm{~Hz}(f \mathrm{r}, 1)$ at $53 \pm 14 \mathrm{~Hz}$ and in all subjects a second resonance $f a r, 2$ at $762 \pm 158 \mathrm{~Hz}$. All subjects showed a welldefined antiresonances $(f a r, 1)$ at $172 \pm 35 \mathrm{~Hz}$. In three subjects the first antiresonance was split into two distinct

Table 3. - Technical quality of the high-frequency impedance measurements using the high-speed interrupter techniques

\begin{tabular}{lcc}
\hline Patient & $\mathrm{n}$ & $\begin{array}{c}f \max \gamma \\
\mathrm{Hz}\end{array}$ \\
\hline 1 & & 1322 \\
2 & 10 & 1379 \\
3 & 9 & 1411 \\
4 & 8 & 1330 \\
5 & 7 & 1395 \\
6 & 8 & 1387 \\
7 & 10 & 1340 \\
8 & 10 & 1444 \\
9 & 10 & 1315 \\
10 & 7 & 1451 \\
11 & 10 & 1387 \\
12 & 10 & 1379 \\
13 & 8 & 1370 \\
14 & 10 & 1443 \\
15 & 10 & 1483 \\
16 & 10 & 1443 \\
17 & 10 & 1443 \\
18 & 10 & 1379 \\
Mean & 10 & 1395 \\
SD & 9.3 & 49 \\
\hline
\end{tabular}

From 10 measurements (inclusion criterion: pressure change $>0.15 \mathrm{kPa}) \mathrm{n}$ measurements showed a coherence $>0.9$ up to a maximal frequency $\left(f_{\max \gamma}\right)$.

Table 2. - Results of high frequency impedance measurements using the high speed interruptor technique

\begin{tabular}{|c|c|c|c|c|c|c|c|c|c|c|c|}
\hline \multirow[t]{2}{*}{ Patient } & \multicolumn{2}{|c|}{$\begin{array}{c}V^{\prime} \operatorname{maxFRC} \\
\mathrm{mL} \cdot \mathrm{s}^{-1}\end{array}$} & \multicolumn{2}{|c|}{$\begin{array}{c}f \mathrm{ar}, 1 \\
\mathrm{~Hz}\end{array}$} & \multicolumn{2}{|c|}{$\begin{array}{c}Z(f) \mathrm{re} \\
\mathrm{kPa} \cdot \mathrm{L}^{-1} \cdot \mathrm{s}\end{array}$} & \multicolumn{2}{|c|}{$\begin{array}{c}f_{\mathrm{ar}, 2} \\
\mathrm{~Hz}\end{array}$} & \multicolumn{2}{|c|}{$\begin{array}{c}Z(f) \operatorname{re}\left(f_{\text {ar }}, 2\right) \\
\mathrm{kPa} \cdot \mathrm{L}^{-1} \cdot \mathrm{s}\end{array}$} & \multirow{2}{*}{$\begin{array}{c}\text { Ratio } \\
f_{\mathrm{ar}, 2 / f_{\mathrm{ar}, 1}}\end{array}$} \\
\hline & mean & $\mathrm{CV}$ & mean & $\mathrm{CV}$ & mean & $\mathrm{CV}$ & mean & $\mathrm{CV}$ & mean & $\mathrm{CV}$ & \\
\hline 1 & 146 & 5.1 & 117.5 & 3.3 & 2.6 & 7 & & & & & \\
\hline 2 & 320 & 4.9 & 162 & 6.7 & 5.3 & 8.8 & 554 & 6.3 & 17.7 & 30.9 & 3.4 \\
\hline 3 & 201 & 3.7 & 161 & 13.5 & 4.6 & 20.8 & & & & & \\
\hline 4 & 149 & 5 & 218.5 & 4.5 & 6.2 & 7.5 & & & & & \\
\hline 5 & 144 & 4.5 & 212.5 & 9.7 & 6.3 & 18.6 & 648 & 11.8 & 30.7 & 48.5 & 3.1 \\
\hline 6 & 409 & 5 & 177.9 & 14.1 & 6.4 & 8.9 & 540 & 6.4 & 23.2 & 26.8 & 3.0 \\
\hline 7 & 268 & 5.4 & 173 & 7.3 & 5.3 & 17 & & & & & \\
\hline 8 & 213 & 6 & 185.8 & 3.8 & 2.9 & 5.3 & & & & & \\
\hline 9 & 183 & 5.3 & 193 & 8.3 & 5.3 & 21.9 & & & & & \\
\hline 10 & 128 & 10.5 & 85.6 & 18.2 & 4.0 & 3.5 & 570 & 5.9 & 10.8 & 5.8 & $6.67 *$ \\
\hline 11 & 92 & 9.9 & 154.5 & 6.4 & 4.8 & 17.9 & & & & & \\
\hline 12 & 79 & 10.4 & 173 & 10 & 4.7 & 20 & & & & & \\
\hline 13 & 87 & 12.1 & 139.9 & 25.1 & 3.6 & 15.8 & & & & & \\
\hline 14 & 89 & 8.4 & 212.9 & 11 & 6.3 & 6.4 & & & & & \\
\hline 15 & 220 & 3.4 & 209 & 5.7 & 7.0 & 10.9 & & & & & \\
\hline 16 & 175 & 4.3 & 198.6 & 11.7 & 4.6 & 16.9 & & & & & \\
\hline 17 & 243 & 4.9 & 152 & 7.1 & 4.8 & 11.5 & & & & & \\
\hline 18 & 356 & 6.7 & 162.8 & 8.8 & 3.8 & 15.4 & 511 & 4.9 & 18.2 & 6.9 & 3.1 \\
\hline mean & 213 & 6.4 & 171.6 & 9.7 & 4.9 & 13 & 564.4 & 7.1 & 20.1 & 23.7 & 3.2 \\
\hline SD & 90 & 2.6 & 34.8 & 5.4 & 1.1 & 5.9 & 51.4 & 2.7 & 7.4 & 18 & 0.2 \\
\hline
\end{tabular}

Values are shown as the mean and coefficient of variation $(\mathrm{CV})$ of 10 measurements. The input impedance $(Z(f))$ antiresonances (high-speed interrupter technique) were described by the frequencies of the first and second antiresonances $\left(f_{\text {ar, }} 1\right.$ and $\left.f_{\text {ar, }, 2}(\mathrm{~Hz})\right)$ and the relative maxima in the real part at $f_{\mathrm{ar}, 1}$ and $f_{\mathrm{ar}, 2}$, respectively $\left(Z(f) \mathrm{re}\left(f_{\mathrm{ar}, 1}\right), Z(f) \mathrm{re}\left(f_{\mathrm{ar}, 2}\right)\right)$. $V^{\prime}$ maxFRC: maximal expiratory flow at functional residual capacity (using rapid compression technique). 
maxima but only one zero-crossing in the imaginary part (subject 8: 113/185 Hz; 10: 86/200 Hz; 12: 140/209 Hz). In five of the infants (as in subject 5, fig. 2) there was a relative maximum in the real part of $Z(f)$ at a frequency $f_{\mathrm{ar}, 2}=690 \pm 180 \mathrm{~Hz}$ that was associated with relative maximum in the imaginary part, but the imaginary part did not cross zero as it does in a well-defined antiresonance. At $1,003 \pm 9.67 \mathrm{~Hz}\left(f_{\mathrm{ar}, 3}\right)$ a well-defined antiresonance was found in all subjects. However, this antiresonance varied within subjects, when the set-up or the face mask was changed (as discussed in more detail below). Therefore, only $Z(f)$ measurements up to $900 \mathrm{~Hz}$ are reported (fig. 3). The short-term repeatability of the first and second antires- onance is given by the $\mathrm{CV}$ (table 2). The $\mathrm{CV}$ of $f$ ar, 1 (9.7 \pm $5.4 \%), f a r, 2(7.1 \pm 2.7 \%)$ and $V^{\prime} \operatorname{maxFRC}(6.4 \pm 2.4 \%)$ in these subjects were not significantly different $(\mathrm{p}>0.01)$, whereas the $\mathrm{CV}$ of $Z(f) \mathrm{re}(f \mathrm{ar}, 1)(13 \pm 5.9 \%)$ and $Z(f) \mathrm{re}(f \mathrm{far}, 2)(23.7 \pm$ $18 \%)$ were higher than the CV of $V^{\prime} \operatorname{maxFRC}(\mathrm{p}<0.01)$.

The technical reliability of the HIT is described by the number of measurement sets (n out of 10) with coherence $\gamma>0.90$ and the maximal frequency up to which $Z(f)$ could be measured with coherence $\gamma>0.9\left(f_{\max } \gamma\right)$ (table 3). In all infants the coherence was $>0.9$ between $32 \mathrm{~Hz}$ and $1,395 \pm 49 \mathrm{~Hz}$, except for a few single frequency points, usually around 350 and $900 \mathrm{~Hz}$. These frequency points were excluded from the analysis.
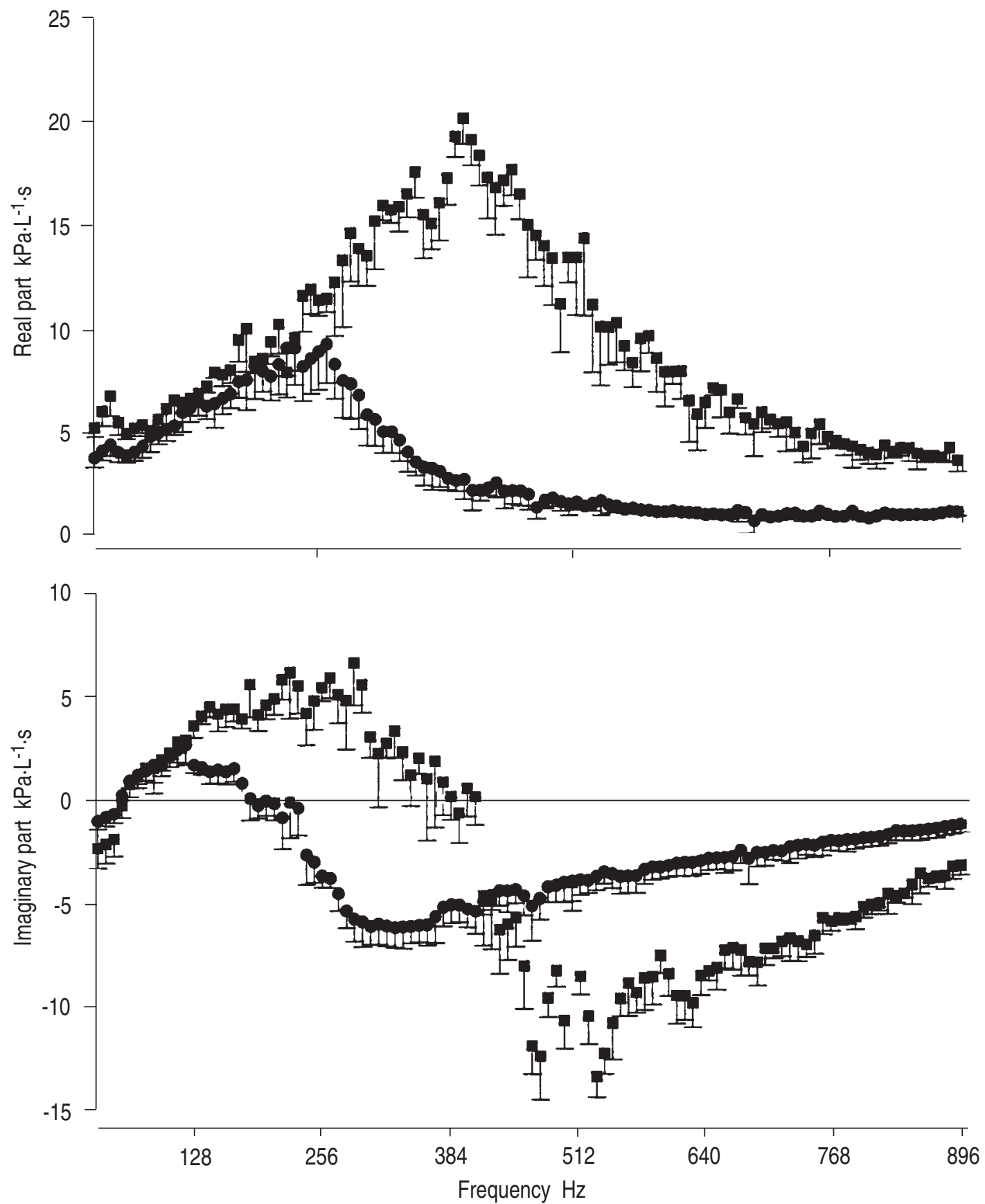

Fig. 4. - High-frequency input impedance $(Z(f))$ measurements (mean and SD of 10 measurements) during room air $(\bullet)$ and $\mathrm{He}-\mathrm{O}_{2}$ breathing $(\boldsymbol{\square})$ in one infant. The antiresonances far, 1 shifted from $193 \mathrm{~Hz}$ to $403 \mathrm{~Hz}$ when breathing gas of low density $\left(\mathrm{He}-\mathrm{O}_{2}\right)$. 

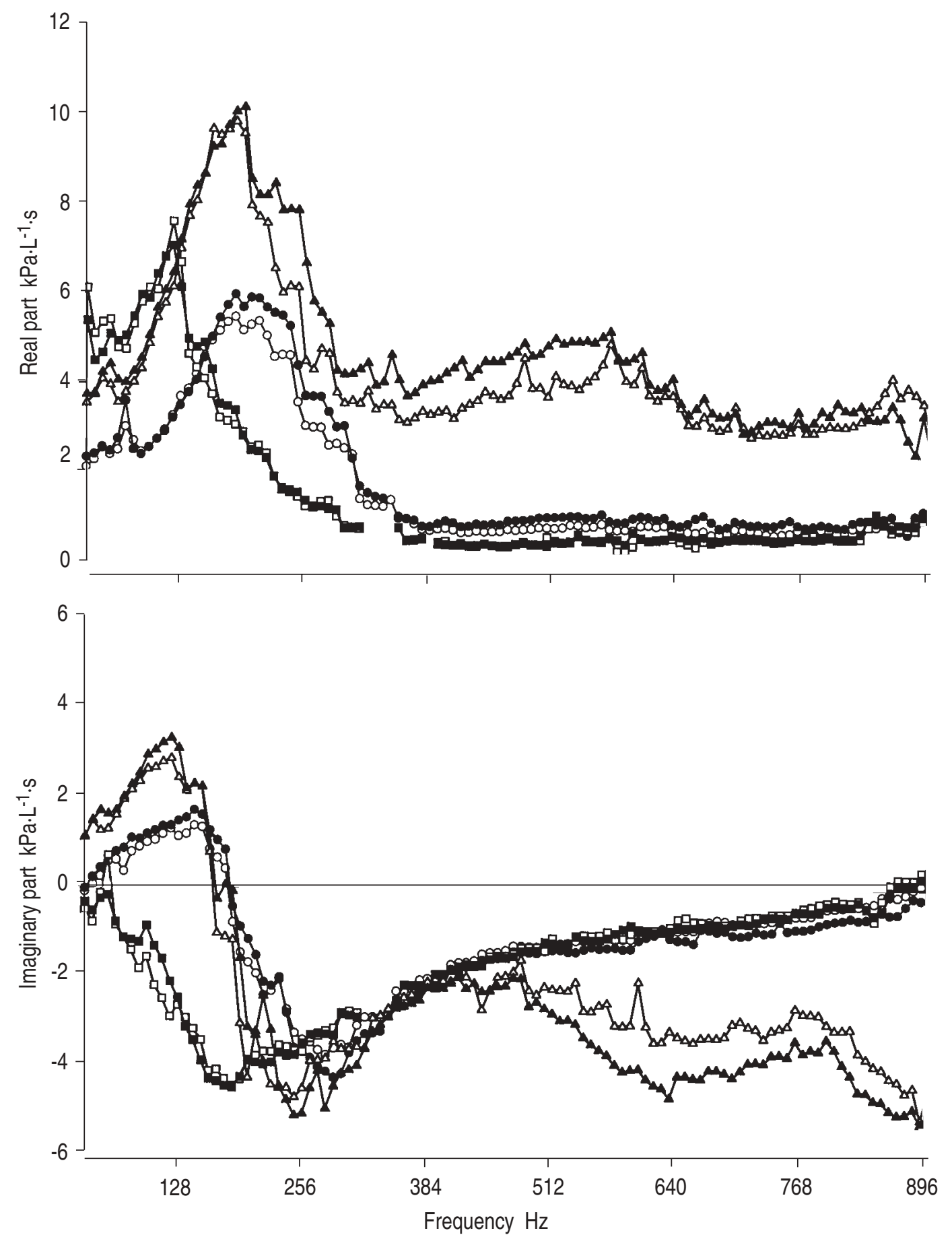

Fig. 5. - Example of five high-frequency input impedance $(Z(f))$ measurements (mean; errors quitted for clarity) in three infants (circles, squares, triangles) before (open symbols) and after (closed symbols) occlusion of one nostril, indicating that the antiresonance in the $Z(f)$ measurements was not significantly influenced by altering the upper airway patency.

\section{Part 2: Measurements during Heliox $\left(\mathrm{He}-\mathrm{O}_{2}\right)$ breathing}

When a gas of lower density $\left(\mathrm{He}-\mathrm{O}_{2}\right)$ was inhaled, $f_{\text {ar, } 1}$ increased from 193 to $403 \mathrm{~Hz}$ (ratio 2.1) in one subject (fig. 4), from 112 to $274 \mathrm{~Hz}$ (ratio 2.4) in the second subject and from 209 to $314 \mathrm{~Hz}$ (ratio 1.5) in the third subject. These results are close to the theoretical value of 1.93 and provide evidence that the first antiresonance is a phenomenon related to wave-propagation velocity within the airways.

\section{Part 3: Influence of nasal patency on $\mathrm{Z}(\mathrm{f})$}

Occluding one nostril had no significant effect on the first antiresonance in all three infants (fig. 5). The differences in $f$ ar, 1 and $Z(f)$ re $\left(f_{\text {ar, }}, 1\right)$ before and after occlusion for the three subjects were 0,0 and $8 \mathrm{~Hz}$ and $-0.5,0.5$ and 0.22 $\mathrm{kPa} \cdot \mathrm{L}^{-1} \cdot \mathrm{s}$ respectively.

\section{Discussion}

Two problems were addressed in this study: firstly, whether high-frequency input impedance in infants can be 
measured by the noninvasive HIT and, secondly, whether high-frequency $Z(f)$ data can provide information about intrathoracic airway mechanics. For this purpose, the nature of the antiresonances in infants had to be elucidated. It has recently been demonstrated in human adults that the frequency of these antiresonances contains information about airway wall properties $[8-11,14]$. The possibility of measuring airway wall mechanics in vivo in infants would, thus, help to elucidate flow limitation phenomena in wheezing disorders in infants, since flow limitation is influenced not only by the airway diameter but also by airway wall compliance [2]. The widely used rapid chest compression technique is not able to distinguish between the effects of airway diameter and airway wall compliance on airflow limitation. Measurement of airway wall properties would help to answer the question of whether only developmental differences in airway size [4] or possibly also developmental differences in airway wall compliance might predispose to wheezing disorders in infancy. It could also explain why bronchodilators can have paradoxical effects in infants [3], bearing in mind that they have the potential to change both airway diameter and airway wall compliance by changing airway smooth muscle tone.

Information about airway wall properties in adults has been extracted from measurements of $Z(f)$ from $5-320 \mathrm{~Hz}$ [11] and in more detail from $8-2000 \mathrm{~Hz}$ in adults [14]. In infants, $Z(f)$ data have never been measured in the frequency range $>256 \mathrm{~Hz}$, and the nature of antiresonance phenomena has never been elucidated. Measurement of $Z(f)$ at these high frequencies was expected to be difficult, because infant airways are small and the system has a relatively high impedance. Therefore, if pressure waves are applied at the airway opening, as in the FOT, the amplitude of the resulting flow will be small and the signal-tonoise ratio will be low. This is particularly true for higher frequencies because of the capacitative shunting into the gas compression compliance of the loudspeaker (FOT) [21]. To overcome these problems a new technique was developed, the HIT [21], which uses a pseudo-step-flow forcing function and enables much higher flow amplitudes at high frequencies than the FOT.

The interrupter technique was invented by NEERGAARD and WIRz [26] and has been modified many times [27-31]. The value of the standard interrupter technique is limited because it only permits the measurement of a Newtonian lung resistance $[30,31]$, but changes in airway opening pressure after airflow interruption can be analysed in more details. JACKSON et al. [28, 29] showed that highly damped pressure oscillations occurred after rapid airflow interruption. ROMERo et al. [32] showed in dogs that an antiresonance in the power spectrum of the airway opening pressure occurred at $\sim 80 \mathrm{~Hz}$ and a gas density-dependent antiresonance occurred at $180 \mathrm{~Hz}$. They specula-ted that these antiresonances correspond to the $C \mathrm{~g}-\mathrm{It}$-tissue resonance $(80 \mathrm{~Hz})$ and the first acoustic resonance $(180 \mathrm{~Hz})$ described by $\mathrm{J}_{\mathrm{ACKSON}}$ and LUTCHEN [7] in the $Z(f)$ spectrum. Only a single antiresonance was found in human adults which, after correction for the mouthpiece length, was close to $180 \mathrm{~Hz}[33,34]$ and it was speculated in analogy that it corresponds to the wave propagation-related antiresonance in the $Z(f)$ spectrum found by $\mathbf{J}_{\text {ACKSON }}$ et al. [11]. Recently, it was shown in a dog lung and in human adults that it is possible to measure high-frequency $Z(f)$ using the new HIT [21], when not only the post-occlu- sional pressure transients but also post-occlusional oscillatory flow transients are measured.

\section{Measurement of $\mathrm{Z}(\mathrm{f})$ in infants using the HIT from 32 to $\sim 1300 \mathrm{~Hz}$}

This was technically possible with a coherence- $\gamma>0.9$ using a pseudostep flow-forcing function generated by the HIT. Two resonances and one antiresonance was found in all of the infants, whereas a second antiresonance was detectable only in five of the subjects. At frequencies over $1,000 \mathrm{~Hz}$ a third antiresonance occurred which was dependent on the set-up and the face mask. The frequency and the real part at this third antiresonance changed when the set-up, the head position and the face mask were varied within the same patient. Furthermore, despite matching the pressure transducers inaccuracies were also expected at about $1,000-1,100 \mathrm{~Hz}$, because the resonant frequency of the solid-state pressure transducers was expected to lie in this frequency range. For these reasons, only $Z(f)$ data up to $900 \mathrm{~Hz}$ were reported.

\section{Physiological interpretation of $\mathrm{Z}(\mathrm{f})$ data below $100 \mathrm{~Hz}$ in infants}

The first resonance frequency $\left(f_{\mathrm{r}, 1}\right)$ was $<32 \mathrm{~Hz}$ in 4 subjects and at $53 \pm 14 \mathrm{~Hz}$ in the others, which is slightly higher than in our previous study [20] $(37 \pm 9 \mathrm{~Hz})$, but similar to the studies of DESAGER et al. [17] and JACKSON et al. [19]. Marchal et al. [15] did not find a resonance in their study, probably because their measurements were not taken to high enough frequencies. MARCHAL et al. [16] found $f_{r}, 1$ at lower frequencies when they used the head generator technique, indicating the effects of extrathoracic airway walls on $f \mathrm{r}, 1$. Also, Sty et al. [18] found $f \mathrm{r}, 1$ to be at much lower frequencies. This might be explained by the fact that they performed measurements under conditions of raised lung volume and induced relaxation (HeringBreuer reflex) in healthy infants. The geometry of the face mask might also have been different in their study.

In the present study, $f \mathrm{r}, 1$ was inversely related to postnatal age; the older the child the lower the first resonance. Based on the Dubois model [22] $f \mathrm{r}, 1$ is given by:

$$
f_{\mathrm{r}, 1}=1 / 2 \cdot\left[C \mathrm{ti}\left(\operatorname{Iaw}+I_{\mathrm{ti}}\right)\right]^{0.5},
$$

where $C$ ti is the tissue compliance, Iaw the airway inertance and $I$ ti the tissue inertance. This dependence on compliance would explain the inverse correlation between $f_{r}, 1$ and age. The frequency dependence of the real part of $Z(f)$ below $f r, 1$ was difficult to assess with the HIT because the lowest frequency measured was $32 \mathrm{~Hz}$. However, this frequency dependence of resistance in infants is influenced not only by parallel inhomogeneity but also by nonrigid behaviour of the upper or central airways [19]. Recent computer predictions by J $\mathrm{ACKSON}_{\text {et }}$ al. [19] suggest that since infant airways are so compliant, the real part could be frequency dependent even in healthy infants, as observed by MARCHAL et al. [15]. Using FOT this frequency dependence of resistance as well as $f_{\mathrm{r}, 1}$ was demonstrated to change in a very complex and unsystematic manner during induced airway obstruction [20].

\section{Physiological interpretation of Z(f) above $100 \mathrm{~Hz}$ in infants}

The most prominent features in the $Z(f)$ above $100 \mathrm{~Hz}$ are the antiresonances. A first antiresonance was found in 
all infants and a second antiresonance in five infants. The frequencies of both the first and second antiresonance showed a CV similar to $V^{\prime}$ maxFRC from the widely used RTC technique, whereas the relative maxima at the anti-resonant frequencies showed a slightly higher variability. The frequency and relative maxima in the real part were not related to age. However the patients were not healthy and so a final conclusion on age dependence cannot be drawn. The first antiresonance occurred at $\sim 170 \mathrm{~Hz}$, which is similar to the findings in adults [11] and to our previous study [20], but higher than reported in the study of J $J_{\text {ACKSON }}$ et al. [19] in healthy infants. The fact that higher antiresonant frequencies were found in infants with wheezing would be consistent with observations in adults with obstructive pulmonary disease [12]. However, while there was a tendency for far,1 to be higher with decreasing $V^{\prime}$ maxFRC and therefore increasing airway obstruction, this correlation was not significant. To understand this more information is needed on the nature of the antiresonances in infants, since in wheezy infants the airways might be very different from those of patients with chronic obstructive pulmonary disease.

The current findings support mainly the hypothesis that the antiresonances are caused by wave-propagation phenomena in the airways, as in human adults. Theoretically, the fact that the antiresonant frequency changed when a gas of lower density $\left(\mathrm{He}-\mathrm{O}_{2}\right)$ was inhaled could be explained either by the interaction of $C \mathrm{~g}$ and $\mathrm{Iti}$ (Dubois model) or by the influence of the average molecular weight of the gas mixture (gas density) on the wave-propagation velocity. In the first case, according to the Dubois model $f_{\text {ar, }} 1$ would be inversely related to $C \mathrm{~g}$ and Iti. Iti should not be affected by a gas of different density, whereas $C \mathrm{~g}$ would change provided the ratio of specific heats of the two different gases are different and the compressions in the alveoli are adiabatic. The differences in specific heat between air (1.4) and $\mathrm{He}-\mathrm{O}_{2}(1.56)$ would result in an $11 \%$ increase in $C \mathrm{~g}$ and a $5 \%$ decrease in $f_{\mathrm{ar}, 1}$ during $\mathrm{He}-\mathrm{O}_{2}$ breathing. Similarly, if the antiresonance were purely related to the gas compression compliance in the face mask $(C \mathrm{~m}), f$ ar, 1 would change, but not by a factor of 2. In the second case, if the antiresonance is related to wave-propagation, $f_{\mathrm{ar}, 1}$ is proportional to the wave-propagation velocity $(v)$. For example, in a rigid tube, far,1 would be $v / 4 L$, where $L$ is the length of the tube. In a rigid tube $v$ is only dependent on gas density and not on diameter, whereas in a compliant tube $v$ is a function of gas density and wall compliance [35]. However, airway wall compliance did not change during the $\mathrm{He}-\mathrm{O}_{2}$ experiment. The ratio of vHe- $\mathrm{O}_{2}\left(64.5 \mathrm{~ms}^{-1}\right)$ and vair $\left(33.3 \mathrm{~ms}^{-1}\right)$ is 1.93 . In the present study far, 1 increased by a factor of $\sim 2$ following $\mathrm{He}-\mathrm{O}_{2}$ breathing, which makes it likely that the antiresonance is related to wave propagation in the airways and not to tissue properties. In this concept antiresonances are often referred as acoustic antiresonances [11].

Assuming a very simple acoustic airway model consisting of a single open rigid airway, the harmonics ( $f_{\mathrm{ar}, 2}, f_{\mathrm{ar}, 3}$, $\left.f_{\text {ar, }} 4 \ldots\right)$ of $f$ ar, 1 would occur at multiples of $3,5,7 \ldots$ times

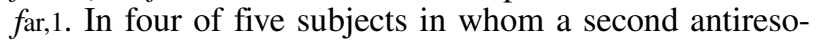
nance $f$ ar, 2 occurred, it was found to occur at a multiple of $\sim 3$ (5 in subject 10 ) of $f_{\mathrm{ar}, 1}$, which would support the hypothesis. However, far, 1 of $171 \mathrm{~Hz}$ would correspond to a mean airway path length of $48.7 \mathrm{~cm}$, which seems too long for an infant. In compliant tubes, far,1 depends not only on airway path length and gas density, but also on the compliance of the tube. The relationship between the wave-propagation velocity in a nonrigid tube and the wall compliance is highly complex and dependent on the frequency of the travelling pressure wave [35]. This might lead to two phenomena: first, $f_{\mathrm{ar}, 1} 1$ is dependent on airway wall compliance and, secondly, the ratio $f$ ar, $2 / f$ ar, 1 might not simply be a harmonic function.

This new evidence that the antiresonances are dependent on wave propagation is interesting from a developmental point of view since high-frequency $Z(f)$ data in human infants correspond more closely to $Z(f)$ in human adults [10, 11] than to $Z(f)$ in animals [7] with lungs of similar size to infant lungs. However, wave-propagation-related antiresonances in human adults are much sharper and narrower. There are at least two possible explanations for this. In wheezy infants parallel inhomogeneities are expected. Since far,1 corresponds to a mean airway pathlength, one would expect to see a bundle of antiresonances that are close together and might originate from different parallel segments. An alternative explanation would be that multiple peaks could occur because of the frequency dependence of wavepropagation velocity in a compliant tube [35]. Both hypotheses would also explain the occurrence of multiple peaks around $f_{\text {ar, }} 1$ in three of the subjects at baseline.

Having elicudated the origin of the antiresonance phenomena, the question remains of whether the high-frequency $Z(f)$ was largely determined by intrathoracic airway geometry or whether the extrathoracic airway significantly influenced the high frequency $Z(f)$. In three subjects, after occlusion of one nostril the high-frequency $Z(f)$ did not change significantly, providing reassuring evidence that upper airway resistance had little influence on the antiresonances. The influence of extrathoracic airway wall compliance on $Z(f)$ data at frequencies below $100 \mathrm{~Hz}$ has been pointed out by several authors $[16,19]$. The current data support the hypothesis that the antiresonances occurring above $100 \mathrm{~Hz}$ are related to wave-propagation phenomena, implying that its frequencies are related to airway wall properties. It must be assumed, that pressure waves are propagated along the entire airway pathlength from the airway opening to the alveolar space. The compliance of the upper airway may, therefore, partly influence wavepropagation velocity and the high-frequency impedance spectrum of the respiratory system. The influence of the upper airway was minimized in the present measurement setting by filling the face mask with putty and stabilizing the cheeks by holding the face mask firmly in place. In order to determine the relative contribution of extrathoracic and intrathoracic airway wall compliance on $f a r, 1$, one must selectively change one or the other. Since airway smooth muscle is the major determinant of intrathoracic airway wall compliance and cholinergic receptors in the extrathoracic airway are only located in vessels and glands [36], methacholine challenge might help to elucidate the situation. This is reported in our accompanying paper.

\section{Conclusions}

A new noninvasive lung function technique, the high speed interrupter technique has been developed, which enables the noninvasive measurement of high-frequency input impedance from $32-1,300 \mathrm{~Hz}$ in infants. Measurements can be performed without the cooperation of the patient within a few seconds. At frequencies between 
$100-900 \mathrm{~Hz}$ two antiresonances were found. At $\sim 1,000$ $\mathrm{Hz}$ there was a third antiresonance, which was artefactual and depended on the set-up and face mask. The first antiresonance was related to wave-propagation velocity in the airways, similar to the situation in human adults. This implies that the frequency of the first antiresonance is a function of airway wall compliance independent of airway diameter. The frequencies of these antiresonances show a similar variability to standard lung function parameters in this age group. The antiresonance was not significantly affected when nasal patency was altered by occluding one nostril. Since the first antiresonance is a function of airway wall compliance and not of airway diameter, it can be used to elucidate developmental differences in airway wall compliance in the first year of life and their consequences for wheezing disorders, and to explore the actions of therapeutic agents that affect airway function.

\begin{abstract}
Acknowledgements: The authors thank A. Fritschi (Gambro AG, Switzerland), who designed the high-speed shutter valve based on our requirements, and B. Suki (Dept of Biomedical Engineering, Boston University), who provided parts of the software to calculate respiratory input impedance (wave tube technique).
\end{abstract}

\section{References}

1. Tepper RS, Morgan WJ, Cota K, Wright A, Taussig LM. Physiologic growth and development of the lung during the first year of life. Am Rev Respir Dis 1986; 134: 513-519.

2. Dawson SV, Elliot EA. Wave speed limitation on expiratory flow - a unifying concept. J Appl Physiol 1977; 43: 498-515.

3. Prendiville A, Green S, Silverman M. Paradoxical response to nebulized salbutamol in wheezy infants, assessed by partial expiratory flow volume curves. Tho$\operatorname{rax} 1987$; 42: 86-91.

4. Martinez F, Morgan WJ, Wright AL, Holberg CJ, Taussig LM. Diminished lung function as a predisposing factor for wheezing respiratory illnesses in infants. $N$ Engl $J$ Med 1988; 319: 1112-1117.

5. Jackson AC, Lutchen KR. Modelling of respiratory system impedances in dogs. J Appl Physiol 1987; 62: 414-420.

6. Lutchen KR, Jackson AC. Reliability of parameter estimates from models applied to respiratory impedance data. J Appl Physiol 1987; 62: 403-413.

7. Jackson AC, Lutchen KR. Physiological basis for resonant frequencies in respiratory system impedances in dogs. J Appl Physiol 1991; 70: 1051-1058.

8. Jackson AC, Suki B, Ucar M, Habib R. Branching airway network models for analyzing high frequency lung input impedance. J Appl Physiol 1993; 75: 217-227.

9. Habib RH, Suki B, Bates JHT, Jackson AC. Serial distribution of airway mechanical properties in dogs: effect of histamine. J Appl Physiol 1994; 77: 554-566.

10. Dorkin HL, Lutchen KR, Jackson AC. Human respiratory input impedances from 4 to $200 \mathrm{~Hz}$ : physiological and modeling considerations. J Appl Physiol 1988; 63: 823-831.

11. Jackson AC, Giurdanella CA, Dorkin HL. Density dependance of respiratory system impedances between 5 and 320 Hz in humans. J Appl Physiol 1989; 67: 2323-2330.

12. Chalker RB, Celli BR, Habib RH, Jackson AC. Respiratory input impedance from $4-256 \mathrm{~Hz}$ in normals and chronic airflow obstruction: comparisons and correlations to spirometry. Am Rev Respir Dis 1992; 146: 570-576.

13. Van Noord JA, Clement J, Van de Woestijne KP, Demedts $\mathrm{M}$. Total respiratory resistance and reactance as a measurement of response to bronchial challenge with histamine. Am Rev Respir Dis 1991; 143: 922-927.

14. Habib RH, Chalker RB, Suki B, Jackson AC. Airway geometry and wall mechanical properties estimated from subglottal input impedance in humans. J Appl Physiol 1994; 77: 441-451.

15. Marchal F, Peslin R, Duvivier C, Gallina C, Crance JP. Mechanics in ventilatory system in sedated infants: Forced oscillations versus single-breath method. Pediatr Pulmonol 1988; 5: 19-26.

16. Marchal F, Peslin R, Duvivier C, Gallina C, Crance JP Measurement of ventilatory mechanical impedance in infants using a head pressure generator. Pediatr Pulmonol 1989; 7: 209-216.

17. Desager KN, Buhr W, Willemen M, et al. Measurement of total respiratory impedance in infants by the forced oscillation technique. J Appl Physiol 1991; 71: 770-776.

18. Sly PD, Hayden MJ, Petak F, Hantos Z. Measurement of low frequency impedance. Am J Respir Crit Care Med 1996; 154: 161-166.

19. Jackson AC, Neff KM, Lutchen KR, Dorkin HR. Interpretation of respiratory system impedances $(4-256 \mathrm{~Hz})$ in healthy infants. Pediatr Pulmonol 1996; 226: 364-375.

20. Frey U, Silverman M, Kraemer R, Jackson AC. High frequency respiratory impedance in infants by forced oscillations. Am J Respir Crit Care Med 1998; in press.

21. Frey U, Suki B, Kraemer R, Jackson AC. Human respiratory input impedance between 32 and $800 \mathrm{~Hz}$ measured by high speed interrupter technique. J Appl Physiol 1997; 82: 1018-1023.

22. Dubois AB, Brody AW, Lewis DH, Burgess BF Jr. Oscillation mechanics of lungs and chest in man. J Appl Physiol 1956; 8: 587-594.

23. Franken H, Clement J, Cauberghs M, Van de Woestijne KP. Oscillating flow of a viscous compressible fluid through a rigid tube: a theoretical model. IEEE BME 1981; 28: 417-420.

24. Michaelson ED, Grassman ED, Peters WR. Pulmonary mechanics by spectral analysis of forced random noise. $J$ Clin Invest 1975; 56: 1210-1230.

25. Clarke JR, Aston H, Silverman M. Evaluation of tidal expiratory flow index in healthy and diseased infants. Pediatr Pulmonol 1994; 17: 285-290.

26. Neergaard K von, Wirz K. Die Messung der Strömungswiderstände in den Atemwegen des Menschen, insbesondere bei Asthma und Emphysem. Z Clin Med 1927; 105: 51-82.

27. Mead J, Whitthenberger JL. Evaluation of the airway interruption technique as method for measuring pulmonary airflow resistance. J Appl Physiol 1954; 6: 408-416.

28. Jackson AC, Milhorn HT. Digital computer simulation of respiratory mechanics. Comput Biomed Res 1973; 6: 27-56.

29. Jackson AC, Milhorn HT, Norman JR. A reevaluation of interrupter technique for airway resistance measurements. J Appl Physiol 1974; 36: 264-268.

30. Bates JHT, Baconnier P, Milic-Emili J. A theoretical analysis of interrupter technique for measuring respiratory mechanics. J Appl Physiol 1988; 64: 2204-2214.

31. Bates JHT, Abe T, Romero PV, Sato J. Measurements of alveolar pressure in closed chest dogs during flow interruption. J Appl Physiol 1989; 67: 488-492.

32. Romero PV, Sato J, Shardonowski F, Bates JHT. High frequency characteristics of respiratory mechanics determined by flow interruption. J Appl Physiol 1990; 69: 1682-1688.

33. Frey U, Schibler A, Kraemer R. Pressure oscillations after flow interruption in relation to lung mechanics. Respir Physiol 1995; 102: 225-237.

34. Frey U, Kraemer R. Analysis of oscillatory pressure transients after flow interruption in healthy and asthmatic children. Pediatr Pulmonol 1995; 19: 379-388.

35. Guelke RW, Bunn AW. Transmission line theory applied to sound wave propagation in tubes with compliant walls. Acoustica 1981; 48: 101-106.

36. Baraniuk JN, Kaliner MA, Barnes PJ. Localisation of M3 muscarinic receptor messenger RNA in human nasal mucosa. Am J Rhinol 1992; 6: 145-148. 